\title{
Perspektif Al-Qur'an tentang Pembebasan Manusia Melalui Pendidikan Akhlak
}

\author{
Fadlil Yani Ainusyamsi \\ Universitas Islam Negeri (UIN) Sunan Gunung Djati Bandung \\ Email: fadlilyani@gmail.com \\ Husni \\ Institut Agama Islam Darussalam (IAID) Ciamis Jawa Barat \\ Email: husni1967@iaid.ac.id
}

Received: January 12, 2021 | Accepted: June 9, 2021

\begin{abstract}
This study aims to elaborate the concepts of the Qur'an about moral education. In addition, this study also aims to understand the concept of human liberation in the Qur'anic perspective. This study uses the literature review method by tracing a number of verses of the Qur'an that are relevant to the theme of the study. In addition to examining relevant verses of the Qur'an, this study is also equipped with a reflection method, which is a method that seeks to reflect the author's knowledge and experience in the current context, so that the author's knowledge and experience are used as a mirror in understanding the realities and problems of Muslims. The results of the study show that efforts to improve the character and behavior of Muslims are to free mankind from ignorance, poverty, and neglect of Islamic moral values.
\end{abstract}

\begin{abstract}
Abstrak
Kajian ini bertujuan untuk mengelaborasi konsep-konsep Al-Qur'an tentang pendidikan akhlak. Selain itu, penelitian ini juga bertujuan untuk memahami konsep pembebasan manusia dalam perspektif qur'ani. Kajian ini menggunakan metode literature review dengan cara menelusuri sejumlah ayat-ayat al-Qur'an yang relevan dengan tema kajian. Selainmengkaji ayat-ayat al-Qur'an yang relevan, kajian ini juga dilengkapi dengan metode refleksi, yaitu suatu metode yang berusaha merefleksikan penetahuan dan pengalaman penulis dalam konteks kekinian, sehingga pengetahuan dan pengalaman penulis digunakan sebagai cermin dalam memahami realitas dan problem umat Islam. Hasil kajian menunjukkan bahwa usaha untuk memperbaiki karakter dan perilaku umat Islam adalah dengan membebaskan umat manusia dari kebodohan, kemiskinan, dan pengabaian terhadap nilai-nilai akhlak Islam.
\end{abstract}




\section{Keywords \\ Al-Qur'an, liberation, akhlâq education}

\section{Pendahuluan}

Tidak bisa dipungkiri bahwa umat Islam di seantero dunia, tak terkecuali di Indonesia, sejak lama dan sampai sekarang masih tetap menghadapi kolonialisme (al-isti'mâriyyah), baik yang bersifat terbuka maupun terselubung. Neokolonialisme, demikian biasa disebut, mewujud dalam pelbagai bentuk seperti penindasan, tekanan, intimidasi dan represi atas umat terjadi di hampir semua belahan dunia (Young, 1995). Proses kolonialisme yang telah berlangsung sangat lama ini telah menyebabkan kehidupan umat Islam menjadi sangat terpuruk yang juga melahirkan penderitaan panjang pada hampir seluruh aspek kehidupan. Kemiskinan, kebodohan, dan ketertinggalan dalam penguasaan ilmu pengetahuan dan teknologi seolah menjadi ciri khas yang melakat pada umat Islam selama bertahun-tahun (Voll, 1982).

Akibat lebih jauhnya adalah berkembangnya suatu kondisi di mana umat Islam selalu menjadi bulan-bulanan kekuatan politik, ekonomi dan media massa internasional. Ketidakmampuan umat Islam dalam mengelola — apalagi mempengaruhi opini publik internasional—ditambah kekuatan media massa barat yang luar biasa pengaruhnya, menyebabkan lahirnya stereotip (at-tashfihiyyah) atas umat Islam yang serba buruk dan negatif. Bagi media massa kafir barat, umat Islam tak lebih dari gerombolan pengacau yang suka menyebarkan kekerasan dan teror. Lebih konyol lagi, media massa barat tidak segan-segan memutarbalikkan makna suatu istilah atau fakta yang kemudian ikut mempengaruhi cara pandang masyarakat internasional terhadap Islam dan umatnya. Misalnya, terhadap istilah "fundamentalisme" yang sejatinya mengandung arti kesetiaan dan tekad untuk berpegang teguh pada nilai-nilai ajaran Islam yang mendasar sesuai dengan petunjuk Al-Qur'an dan Sunnah Rasulullah Saw, tetapi dalam berbagai pemberitaan dan opini internasional, istilah "fundamelisme" mengalami pembelokkan makna menjadi faham keagamaan yang sarat dengan citra negatif seperti kekerasan, terorisme dan peperangan.

Di tingkat nasional, nasib umat Islam Indonesia sesungguhnya tidak jauh berbeda dengan umat Islam di negeri-negeri lain. Kebanyakan dari umat Islam masih miskin, bodoh, mudah diadu domba dan diprovokasi, serta gampang terseret ke dalam arus "sampah" modernisasi yang menyesatkan (Muslim, 2003). Sebagian besar dari umat Islam tidak hanya miskin harta tetapi juga miskin iman. Umat Islam bodoh dan tertinggal jauh dalam penguasaan ilmu pengetahuan dan teknologi, bahkan umat 
Islam juga bodoh dan hanya tahu sedikit tentang samudera ilmu-ilmu keIslam-an yang kaya. Umat Islam tidak memilki kearifan untuk sekadar memahami siapa dirinya sesungguhnya dan lingkungan sosial di mana mereka hidup. Jangankan kemampuan membedakan berbagai gejala dan fakta secara sophisticated (mu'aqqad) atau menggunakan metode analisis (mode of analysis, shîghat at-tahlîl) dalam melihat fenomena di sekitarnya secara objektif dan jujur, sekadar membedakan yang hitam dari yang putih, atau yang benar dari yang salah pun umat Islam sering tidak mampu (Bisri \& Husni, 2020; Husni, 2019b, 2019a; Husni \& Bisri, 2020; Husni \& Setiawan, 2018).

Akibat kebodohannya, mayoritas umat di tanah air belum mampu membedakan mana ajaran Islam yang asli dan benar, dan mana tradisitradisi dan budaya-budaya yang sesungguhnya tidak ada sangkut-pautnya dengan Islam (Sofwan, 2018). Akibatnya sebagian besar dari umat Islam masih tetap memelihara tradisi-tradisi yang disinyalir mengandung unsurunsur khurafat dan bid'ah, yang akhir-akhir ini justru disemarakkan lagi oleh sebagian elit politik umat Islam. Wajar apabila krisis multidimensional yang dihadapi tidak kunjung berakhir, karena umat Islam tidak menggunakan acuan atau frame of reference (ithâru shûrah al-murâja'ah) yang benar dan dapat dipertanggungjawabkan menurut agama dan akal sehat, malah sebaliknya sebagian dari umat Islam lebih percaya kepada kekuatan mistik semisal ruwatan atau memohon berkah dari arwah para leluhur.

Kombinasi berbagai belenggu yang dihadapi umat-mulai dari kebodohan, kemiskinan, lemahnya iman (adh'âf al-îmân), mudah diadudomba dan diprovokasi, hingga bercampurnya yang hak dengan yang batil-pada akhirnya tidak hanya melemahkan kekuatan umat pada level lokal, nasional maupun global; lebih jauh dari itu, dalam jangka panjang umat akan selalu menjadi bulan-bulanan kekuatan kaum kafir yang mendominasi sektor-sektor penting ekonomi, politik, budaya dan media massa.

\section{Metode}

Kajian ini menggunakan metode literature review dengan cara menelusuri sejumlah ayat-ayat al-Qur'an yang relevan dengan tema kajian. Selainmengkaji ayat-ayat al-Qur'an yang relevan, kajian ini juga dilengkapi dengan metode refleksi, yaitu suatu metode yang berusaha merefleksikan penetahuan dan pengalaman penulis dalam konteks kekinian, sehingga pengetahuan dan pengalaman penulis digunakan sebagai cermin dalam memahami realitas dan problem umat Islam. 


\section{Hasil Penelitian dan Pembahasan}

\section{Pendidikan Akhlak: Perspektif Al-Qur'an}

Salah seorang mantan Ketua Umum MUI Pusat, Ali Yafie, pernah menyatakan bahwa krisis multidimensional yang dialami bangsa Indonesia yang sampai saat ini di awal tahun 2001 masih mendera bangsa Indonesia, tiada lain disebabkan dan berawal dari krisis moral dan etika yang melanda negeri ini (Yafie, 1994). Dia sangat percaya bahwa krisis ekonomi, sosial, dan politik di negeri dengan mayoritas penduduk muslim ini berpangkal dari lunturnya tata nilai moral dan etika yang seharusnya memandu dan menjadi acuan umat Islam dalam bersikap, berperilaku dan bertindak sehari-hari. Akibat dari krisis multidimensional itu, masyarakat Indonesia seolah kehilangan pegangan dan acuan moral dan etik.

Para pengamat biasa menyebut bahwa kondisi dan situasi masyarakat Indonesia sedang mengalami periode transisi yang biasa ditandai dengan munculnya gejala anomali-anomali sosial, di mana tata nilai lama semakin ditinggalkan masyarakat, tetapi tata nilai baru yang mereka harapkan belum terbentuk. Maka, banyak di antara anggota masyarakat Indonesia yang kehilangan pegangan dan acuan moral dan etik. Kondisi yang sesungguhnya sudah sangat rawan ini masih diperparah oleh lemahnya upaya penegakkan hukum di tengah masyarakat.

Atas dasar itu, barangkali umat Islam sepakat bahwa bangsa ini perlu sesegera mungkin kembali kepada tata nilai yang mampu membimbing, menuntun, memandu dan memberi petunjuk kepada umat Islam. Kembali kepada sistem dan tata nilai yang universal, yang tidak dibatasi oleh tempat dan waktu dan yang tidak luntur karena perkembangan zaman.

Bangsa Indonesia tentu tidak ingin menjadi masyararakat tanpa moral, etik dan akhlak. Sebab, sebuah bangsa tanpa akhlak, moral dan etik, sejatinya bangsa itu telah punah, seperti diungkapkan seorang penyair Mesir, Syauqi Bey: "Keberadaan suatu bangsa (ditentukan) oleh tegaknya akhlak. Dan jika akhlak telah hilang dari mereka, maka sesungguhnya bangsa itu punah" (Al-Maqshud \& Al-Ghany, 1993).

Menyadari pentingnya akhlak, moral dan etika bagi eksistensi sebuah bangsa yang didukung oleh keyakinan kuat bahwa krisis multidimensional yang dialami bangsa Indonesia bermula dari adanya krisis moral, etik dan akhlak, maka kembali kepada tata nilai yang adiluhung menjadi prasyarat kondisi yang tidak bisa ditawar-tawar lagi (conditio sine qua non). Bagi bangsa Indonesia, tata nilai adiluhung yang dimaksud tiada lain adalah tata nilai Islam yang menyeluruh (kâffah), 
sebagai manhaj al-hâyat atau way of life, acuan dan kerangka tata nilai kehidupan bangsa Indonesia. Tata nilai Islam yang kâffah tersebut tidak hanya baik untuk dijadikan landasan akhlak, moral dan etik, tetapi juga karena sifatnya yang universal menjadikan tata nilai Islam selalu kondusif dan aplikatif untuk semua masyarakat, bangsa dan zaman. Tata nilai Islam tidak akan pernah lekang oleh terik panas atau lapuk oleh hujan. Dengan tata nilai Islam, masyarakat tidak akan pernah mengalami anomi-anomi, yang bisa menyebabkan masyarakat kehilangan pegangan, acuan dan pedoman hidup.

Hal itu disebabkan karena tata nilai Islam tiada lain adalah AlQur'an, yang juga menjadi akhlak Rasulullah saw. Sebagaimana diriwayatkan dalam sebuah hadis, di mana Sa'id ibn Hisyam berkata, "Aku datang menemui 'Aisyah r.a., lalu bertanya kepadanya mengenai akhlak Rasulullah saw. 'Aisyah menjawab, 'Apakah engkau membaca Al-Qur'an?' Aku jawab, 'Benar, aku membaca Al-Qur'an.' 'Aisyah berkata, 'Akhlak Rasulullah saw adalah Al-Qur’an. Sesunbgguhnya Al-Qur'an mengajarinya adab, seperti firman Allah:

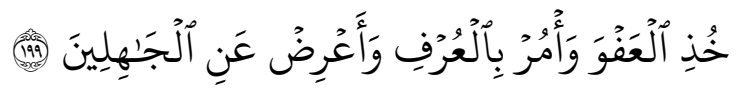

Jadilah engkau pemaaf, suruhlah orang mengerjakan yang baik, dan berpalinglah dari orang-orang yang bodoh (Q.S. Al-A'raf:199)

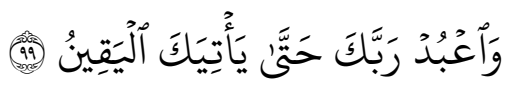

Sesungguhnya Allah menyuruh (kamu) berbuat adil, berbuat kebajikan dan memberi kepada kaum kerabat dan melarang dari perbuatan keji, kemunkaran dan permusuhan (Q.S. An-Nahl:90)

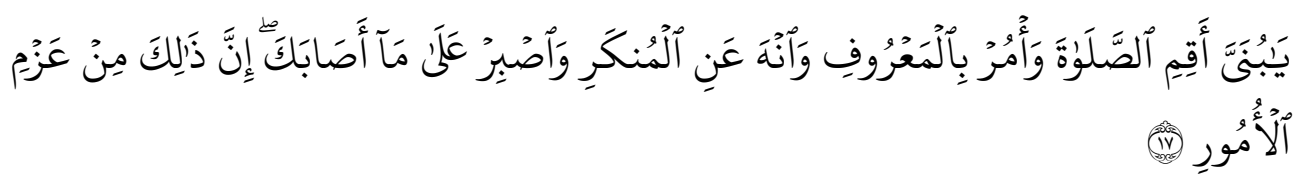

Hai anakku, dirikanlah shalat dan suruhlah (manusia) mengerjakan yang baik dan cegahlah (mereka) dari perbuatan yang mungkar dan bersabarlah terhadap apa yang menimpa kamu. Sesungguhnya yang demikian itu termasuk hal-hal yang diwajibkan (oleh Allah) (Q.S. Luqman:17).(AlMarâghi, 1979; Al-Zuhaylî, 1999; Katsir, 1987; Shihab, 2016)

Karena tata nilai Islam tiada lain adalah Al-Qur'an yang juga menjadi akhlak Rasulullah saw, sedangkan Al-Qur'an selalu dipelihara dan dijaga (oleh Allah) dari segala bentuk penyimpangan dan kerusakan:

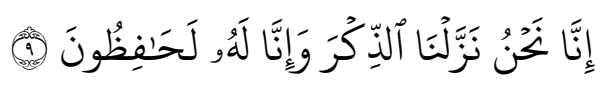


“Sesungguhnya Kami-lah yang menurunkan Al-Qur'an dan sesungguhnya kami benar-benar memeliharanya" (Q.S. Al-Hijr:9).

Maka, tata nilai Islam akan selalu eksis, kondusif dan aplikatif sepanjang Al-Qur'an tetap dipedomani sebagai petunjuk dan tuntunan hidup. Bagi mereka yang mau mendalami dan menelaah Al-Qur'an, pastilah akan menemukan berbagai petunjuk dan tuntunan hidup. Petunjukpetunjuk dan tuntunan-tuntunan hidup yang termaktub dalam Al-Qur'an mencakup berbagai aspek kehidupan manusia, baik yang menyangkut hubungan manusia dengan Khâliq, hubungan manusia dengan manusia, maupun hubungan manusia dengan alam secara keseluruhan. Lebih-lebih jika umat Islam bersedia menelaah dan mendalami hadis-hadis Nabawi, umat Islam pun akan menemukan berbagai nasihat dan tauladan mulia dari Rasulullah saw. Dalam suatu hadis diriwayatkan bahwa Mu'adz ibn Jabal r.a. berkata, "Rasulullah saw berwasiat kepadaku. Dia bersabda: "Aku wasiatkan kepadamu agar bertakwa kepada Allah, berkata benar, menepati janji, menunaikan amanah, meninggalkan pengkhianatan, menjaga hubungan baik dengan tetangga, mengasihi anak yatim, berkata lembut, memulai salam, berbuat baik, pendek angan-angan, meneguhkan keimanan, mempelajari Al-Qur'an, mencintai akhirat, merasa gelisah terhadap penghisaban, dan merendahkan hati. Aku melarang kepadamu dari mencaci orang yang bijak, mendustakan orang jujur, menaati pendosa, durhaka kepada pemimpin yang adil, atau membuat kerusakan di muka bumi. Aku wasiatkan kepadamu agar bertakwa kepada Allah pada setiap batu, pohon, dan tanah. Hendaklah pada setiap dosa engkau datangkan tobat, yang rahasia dengan rahasia dan yang terang-terangan dengan terang-terangan" (Al-Marâghi, 1979)

Tata nilai Islam yang bersumber pada Al-Qur'an dan juga Sunnah Rasulullah saw. memiliki ketinggian karakteristik yang mencakup landasan-landasan yang bersifat asasi serta memuat acuan-acuan yang bersifat praktis. Sebagai tata nilai yang bersifat Ilahiyyah, tata nilai Islam memiliki karakteristik-karakteristik yang sekaligus melebihkannya dari tata nilai yang dikonstruksi manusia.

Pertama, syari'at Islam adalah tata nilai, aturan dan norma ciptaan Allah, Zat yang mengetahui segala sesuatu yang dibutuhkan oleh manusia. Tata nilai Islam diciptakan sesuai dan selaras dengan sendi-sendi kemanusiaan, baik manusia sebagai individu maupun manusia sebagai masyarakat. Oleh sebab itu, tidak mungkin terjadi pertentangan antara tata nilai Islam dengan fitrah kemanusiaan. Firman Allah:

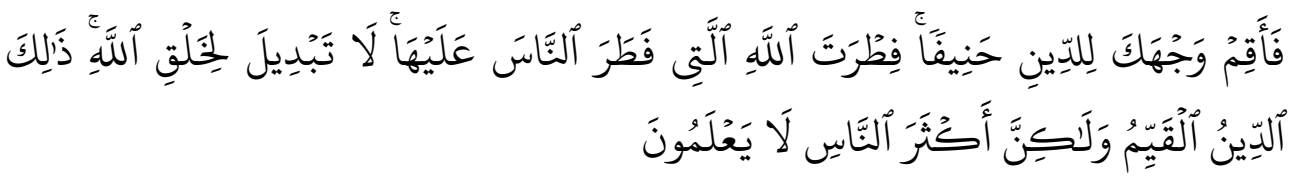


"Maka hadapkanlah wajahmu dengan lurus kepda Agama (Allah); (tetaplah atas) fitrah Allah yang telah menciptakan manusia menurut fitrah itu. Tidak ada perubahan pada fitrah Allah. (Itulah) agama yang lurus; tetapi kebanyakan manusia tidak mengetahui” (Q.S. Al-Rum:30).

Kedua, tata nilai Islam diciptakan dengan tujuan untuk kebahagiaan dan kesejahteraan umat manusia, sehingga terpelihara agamanya, dirinya, akalnya, kehormatannya, dan harta bendanya. Tata nilai Islam selalu memuat perintah untuk berbuat yang ma'ruf, mencegah dari perbuatan yang munkar, menghalalkan yang baik-baik, dan mengharamkan yang buruk-buruk. Firman Allah:

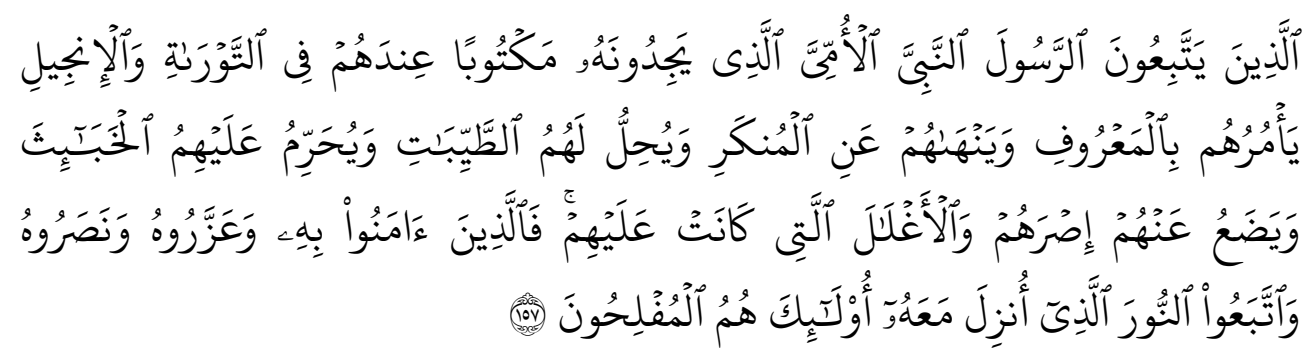

"(Yaitu) orang-orang yang mengikuti rasul, Nabi yang ummi yang (namanya) mereka dapati tertulis di dalam taurat dan Injil yang ada di sisi mereka, yang menyuruh mereka mengerjakan yang ma'ruf dan melarang mereka dari mengerjakan yang munkar dan menghalalkan mereka kepada yang baik dan mengharamkan mereka dari yang buruk dan membuang dari mereka beban-beban dan belenggu yang ada pada mereka. Maka orangorang yang beriman kepadanya, memuliakannya, menolongnya dan mengikuti cahaya yang terang yang diturunkan kepadanya (Al-Qur'an) mereka itulah orang-orang yang beruntung" (Q.S. Al-A'raf:157).

Ketiga, tata nilai Islam bersifat mencakup seluruh aspek kehidupan manusia (syumûliyah). Ia mencakup seluruh sistem keyakinan, etika, moral, hukum, pemikiran dan ilmu pengetahuan, sistem keluarga, ekonomi, sosialpolitik dan lain sebagainya. Tidak ada satu aspek pun dari kehidupan manusia yang luput dari jangkauan tata nilai Islam. Kalaupun tidak diatur secara terperinci, setidaknya terdapat landasan yang bersifat asasi dan prinsipil. Itulah kesempurnaan tata nilai Islam yang tidak tertandingi oleh sistem dan tata nilai mana pun juga.

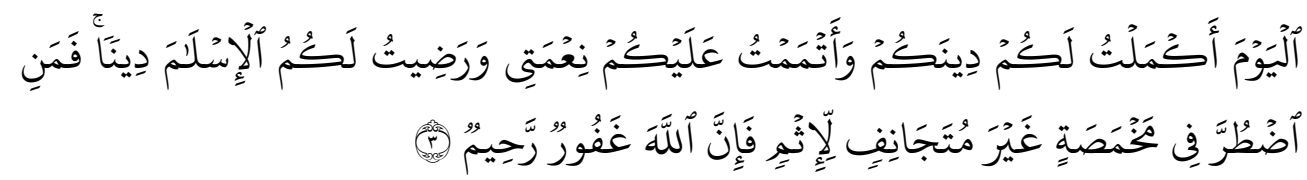

"Pada hari ini telah Kusempurnakan untuk kamu agamamu, dan telah Ku-cukupkan kepadamu nikmat-Ku, dan telah Ku-ridhai Islam itu jadi 
agama bagimu. Maka barang siapa terpaksa karena kelaparan tanpa sengaja berbuat dosa, sesungguhnya Allah Maha Pengampun lagi Maha Penyayang" (Q.S. Al-Maidah:3).

Berdasarkan keunggulan-keunggulan karakteristik tata nilai Islam tersebut dihubungkan dengan kondisi dan situasi bangsa ini, bangsa Indonesia berhadapan dengan sebuah realitas masyarakat yang memperihatinkan. Prihatin karena di satu sisi bangsa Indonesia memiliki perangkat tata nilai yang luhur dan adiluhung, yaitu tata nilai Islam; tetapi di sisi lain bangsa Indonesia berhadapan dengan realitas masyarakat yang hampir-hampir anarkhis, kurang berakhlak, tak peduli pada hukum, dan hampir-hampir menjadi masyarakat biadab.

Oleh karena, sebelum masyarakat Indonesia benar-benar menjadi anarkhis, seyogyanya bangsa Indonesia kembali kepada tata nilai Islam, yaitu tata nilai yang bersumber pada Al-Qur'an dan Sunnah Rasul yang selalu sesuai dan selaras dengan fitrah manusia dan fitrah masyarakat.

\section{Al-Qur'an Menuju Pembebasan Umat}

Mencermati pelbagai belenggu yang dihadapi umat, maka diperlukan komitmen kuat dan sungguh-sungguh untuk membebaskan umat melalui upaya menyemarakkan kembali doktrin dakwah -suatu doktrin dan prinsip Qur'ani utama untuk menyelamatkan umat manusia dari berbagai belenggu kemusyrikan, kebodohan, kemiskinan, kezaliman dan ketidakadilan. Menyemarakkan kembali prinsip dan doktrin dakwah tiada lain adalah upaya revivalisasi dan revitalisasi semangat Muhammad Rasulullah Saw dalam menyebarkan Islam dan membebaskan bangsa Arab dari belenggu-belenggu seperti di sebutkan di atas. Kesuksesan Muhammad Saw dalam mendobrak faham politeisme bangsa Arab dan membebaskan mereka dari tirani perbudakan, belenggu feodalisme, dan kekuasaan yang represif tidak cukup hanya dikagumi sebagai warisan sejarah yang monumental; tetapi menjadi kewajiban setiap umat untuk meniru, menghidupankan dan meneruskannya dan kembali (Arifin, 2011; Lowy, 2013).

Penulis yakin bahwa komitmen umat Islam untuk berdakwah masih tetap berkobar-kobar dan tidak akan pernah surut. Sayangnya, dakwah yang diahami masih terlalu sempit dan lebih terfokus pada kegiatan tabligh, cemarah, pidato dan kegiatan-kegiatan sejenis lainnya. Umat Islam belum berhasil menjadikan prinsip dan doktrin dakwah sebagai sebuah "gerakan" (harakah) umat Islam yang memiliki dua kekuatan sekaligus, yaitu (1) memperjuangkan dan mewujudkan masyarakat tauhid yang berkeadilan, dan (2) mendobrak dan melakukan perlawanan atas berbagai tirani dan belenggu. Gerakan dakwah (harakah ad-da'wah) yang tidak hanya menyeru kepada kebenaran dan kebaikan, melainkan juga keberanian 
melakukan perlawanan terhadap segala kejahatan dan kebatilan inilah yang kurang lebih penulis maksudkan sebagai "dakwah yang membebaskan" sesuai dengan prinsip "hisbah" al-amru bi al-ma'ruf dan an-nahyu 'an almunkar.

Pentingnya membangun gerakan "dakwah yang membebaskan" tidak hanya dilatarbelakangi oleh kondisi umat Islam saat ini yang serba tertindas, terbelenggu dan menghadapi ketidakadilan di hampir semua sektor kehidupan; melainkan dilatari pula oleh sebuah keyakinan tentang hakikat dakwah Muhammad Rasulullah Saw, yang tiada lain adalah upaya pembebasan umat manusia dari faham politeisme, belenggu sosial ekonomi yang feodalistik, serta tirani kekuasaan kaum kafir Quraisy yang represif.

Bukankah fenomena keagamaan, sosial, ekonomi dan politik yang sekarang dihadapi tidak jauh berbeda dengan fenomena masyarakat jahiliyah pada masa Muhammad Saw. masih di kota Mekah? Bukankah sampai saat ini umat Islam masih berhadapan dengan kecenderungan keberagamaan yang belum sepenuhnya steril dari sikap dan perilaku "syirk"; fenomena sosial kemasyarakatan yang amoral; perkembangan sektor ekonomi kapitalis-feodalistik yang hanya menguntungkan segelintir orang kaya; serta kekuasaan politik dan hukum yang korup, represif, dan zalim. Bukankah masyarakat yang bertauhid dan berkeadilan hanya akan terwujud apabila umat Islam bisa keluar dan membebaskan diri dari belenggu-belenggu tersebut? Di sinilah umat Islam perlu menggelorakan semangat gerakan dakwah yang mampu memberikan kekuatan progresif (quwwah al-mutaqaddim) kepada semua umat, sehingga umat Islam memiliki keberanian untuk melawan berbagai belenggu yang dihadapinya.

Sikap pasrah dan menerima begitu saja ketidakadilan dan kezaliman yang dilakukan oleh penguasa politik, ekonomi dan sosial budaya di tingkat lokal, nasional maupun global yang sekarang melanda kebanyakan umat Islam, sejatinya tidak hanya bertentangan dengan hakikat kemanusiaan yang sesungguhnya, tetapi juga tidak sesuai dengan semangat tauhid yang menyatakan bahwa kepasrahan dan penghambaan hanya pantas dilakukan manusia atas Rabb-nya dan tidak kepada selain-Nya.

\section{Kesimpulan}

Konsep dakwah yang membebaskan harus mampu memberikan kesadaran (asy-syu'ur) penuh kepada umat, bahwa hakikat kemanusiaannya tiada lain adalah hamba Allah, dan oleh karenanya hanya kepada Allah-lah ia pasrah, menghamba dan mempersembahkan loyalitas mutlaknya. Dengan kesadaran seperti itu, maka dalam diri umat tertanam jiwa tauhid yang sesungguhnya, yang sanggup melakukan perlawanan terhadap segala 
usaha penindasan, intimidasi, kezaliman dan represi. Di sisi lain, umat juga memiliki semangat menggelorakan panji-panji tauhid, keadilan, perdamaian dan kesejahteraan. Konsepsi dakwah ini memandang manusia sebagai makhluk Allah yang memiliki fitrah, bersifat aktif dan dinamis. Manusia bukanlah makhluk yang terbebani oleh warisan dosa pendahulunya. Ia adalah makhluk yang bertanggung jawab atas segala amal dan perbuatannya sendiri, sesuai dengan firman Allah: "Tiap-tiap diri bertanggung jawab atas apa yang telah diperbuatanya". (Q.S. AlMudatstsir : 38). Ia sendirilah yang akan menentukan tinggi rendah kualitas imannya, "maka barang siapa yang ingin (beriman) hendaklah ia beriman, dan barang siapa yang ingin (kafir), biarlah ia kafir." (Q.S. AlKahfi : 29).

\section{DAFTAR PUSTAKA}

Al-Maqshud, A., \& Al-Ghany, A. (1993). Al-Akhlaq: Baina Falasifah alYunan wa Hukama al-Islam. Maktabah al-Zahra.

Al-Marâghi, A. M. (1979). Tafsîr al-Marâghî. Dar al-Fikr.

Al-Zuhaylî, W. (1999). Tafsir Al-Wajiz. Dar al-Kutub al-Haditsah.

Arifin, A. (2011). Tafsir Pembebasan, Metode Interpretasi Progresif Ala Farid Esack. Aura Pustaka.

Bisri, H., \& Husni, H. (2020). The Influence of Teacher's Multicultural Awareness on "Santri" Learning Activities. Journal of Critical Reviews, 7(7), 133-138. https://doi.org/10.31838/jcr.07.07.21

Husni. (2019a). Konsep Ihsân dalam Wacana Pendidikan Islam. TAJDID, 26(1), 1-12. https://doi.org/10.36667/tajdid.v26i1.317

Husni. (2019b). Moderate Muslims' Views on Multicultural Education, Freedom of Expression, and Social Media Hate Speech: An Empirical Study in West Java Indonesia. Jurnal Penelitian Pendidikan Islam, 7(2), 199-224. https://doi.org/10.36667/jppi.v7i2.370

Husni, H., \& Bisri, H. (2020). Religious Community Responses to COVID 19: Case Study on Muslim Small Community. International Journal of Psychosocial Rehabilitation, 24(8). https://www.psychosocial.com/article/PR281038/25833/

Husni, \& Setiawan, I. (2018). Hermeneutics Paradigm in Religious Research. Religious Studies: An International Journal, 6(2). https://fsshjournal.org/index.php/jrs/article/view/29 
Katsir, I. (1987). Tafsîr al-Qur'ân al-'Adhîm. Dâr al-Kutub al-'Ilmiyah.

Lowy, M. (2013). Teologi Pembebasan: Kritik Marxisme \& Marxisme Kritis. INSISTPress.

Muslim. (2003). Ilmu Islam Terapan Menggagas Paradigma Amali dalam Agama Islam. Pustaka Pelajar.

Shihab, M. Q. (2016). Tafsir al-Misbah. Mizan.

Sofwan, M. (2018). Problematika Dunia Pendidikan Islam Abad 21. Jurnal Kependidikan, 46(2), 271-280.

Voll, J. O. (1982). Islam Continuity and Change in The Modern World. Westviem.

Yafie, A. (1994). Menggagas Fiqh Sosial: Dari Soal Lingkungan Hidup, Asuransi hingga Ukhuwah. Mizan.

Young, R. (1995). Colonial Desire: Hybridity in Theory, Culture, and Race. Routledge. 
